\title{
Análise de um Modelo VEC para Explicar as Variações da Taxa de Câmbio
}

\author{
Angelo Fernando Fiori Camila Cristina Lopes \\ Área de Ciências Exatas e Ambientais, Pós-Graduação Lato Sensu em Matemática Financeira, \\ UNOCHAPECÓ \\ 89809-000, Av. Senador Atílio Fontana, 591e, Chapecó, SC \\ E-mail: an@unochapeco.edu.br; camila.lopes@unochapeco.edu.br
}

\begin{abstract}
Resumo: Em economias globalizadas como as de hoje, há a necessidade de haver uma moeda de troca internacional. Esta moeda hoje é representada pelo dólar americano. O dólar é, portanto, um fator determinante na economia de países com economias abertas ao comércio internacional, como a brasileira. Assim, objetiva-se com este trabalho verificar quais são os fatores que mais afetam as variações no dólar, buscando analisar a interferência das importações, exportações, taxa Selic e dos investimentos estrangeiros nas variações da taxa de câmbio. Para isso utilizou-se conceitos econométricos e um modelo de previsão VEC para as séries de tempo em questão, onde foi possível verificar que em longo prazo as importações e exportações afetam de maneira mais decisiva nesta variação enquanto em curto prazo as alterações da taxa de juros e dos investimentos externos fazem a taxa variar mais.
\end{abstract}

\section{Introdução}

Numa economia cada vez mais global, ocorrem muitas negociações ao longo de períodos fixos as quais determinam a oferta e a procura por produtos/serviços bem como a valorização ou desvalorização das moedas. Nos últimos anos necessitou-se de uma moeda global para tais negociações e, assim, surge a importância do dólar americano para a economia internacional.

A taxa de câmbio expressa a relação em unidades de uma moeda com a unidade de outra moeda. Se a quantidade de unidades de determinada moeda aumentar em relação à outra, diz-se que essa moeda se desvalorizou ou se depreciou; caso essa quantidade se reduza, diz-se que a moeda apreciou ou valorizou. A valorização do câmbio reduz a competitividade dos produtos no mercado externo, diminui a rentabilidade das exportações e inibe investimentos para a exportação. Assim, quando o dólar está desvalorizado em relação à moeda nacional (real, no caso do Brasil) se torna mais fácil importar produtos do exterior, o que aumenta a competitividade com produtos similares internamente. Todos os produtos são importados em dólar e que de maneira praticamente direta são repassados aos seus consumidores (através de preços baixos ou altos). Algo semelhante acontece com as exportações, no entanto elas favorecem a balança comercial já que aumentam a entrada de dólar no país, possibilitando a ele administrar melhor sua economia com relação aos outros países bem como suas relações comerciais nacionais.

Quando a confiança do investidor estrangeiro no Brasil (chamado de risco-país) está abaixo da média, não há entrada de dólar o que, devido a sua baixa circulação interna, valoriza o real. Isso anima investidores mais ousados a aproveitar sua moeda forte para reinjetar dólares no Brasil. Da mesma forma, quando o dólar está em baixa, investidores nacionais investem no exterior.

Segundo Blanchard (1999) a política monetária pode ser definida tanto em termos de oferta de moeda quanto em taxa de juros. No Brasil, a taxa básica de juros usada como referência para diversos reajustes é a Selic. Quanto mais dólares entram no país, menor a cotação dessa moeda por aqui. Então, o aumento na taxa Selic pode diminuir a cotação do dólar no curto prazo, sendo que o inverso repele o dólar do país e com isso seu valor dispara. Ao aumentar e diminuir a Selic, o governo influencia diretamente no consumo e com isso nas importações e exportações brasileiras, no poder de compra e na dívida pública entre outros aspectos.

No Brasil, o dólar regula preços e taxas além de implicar diretamente nas ações do Banco Central para com os diversos segmentos da economia nacional. Ele é afetado especialmente 
pelos fatores acima citados, que compreendem importações, exportações, investimentos estrangeiros e taxa Selic (Sistema Especial de Liquidação e de Custódia).

Busca-se, assim, a partir de um modelo VEC, verificar de que forma esses aspectos afetam a taxa de câmbio. Pra isso este trabalho apresenta o modelo econométrico utilizado e as análises possíveis a partir dele, além das considerações acerca do trabalho e do modelo.

\title{
O modelo econométrico a ser utilizado
}

Quando em 1980 o economista Christopher Albert Sims utilizou em um de seus trabalhos os modelos vetoriais autorregressivos (VAR), acabou por gerar uma rápida disseminação destes modelos especialmente em investigações empíricas na área de macroeconomia. Esta rápida expansão dos modelos VAR "deriva, em grande medida, da percepção de que tais modelos permitem analisar as interrelações entre múltiplas variáveis a partir de um conjunto mínimo de restrições de identificação" (CAVALCANTI, 2010).

A determinação do modelo econométrico a ser estimado será feita através de uma análise multivariada, que consiste em

\begin{abstract}
[...] encontrar comportamento de padrões e relações entre diversas variáveis simultaneamente, o que permite prever o efeito que a mudança de uma variável terá sobre outras variáveis bem como sobre a resposta final. Ainda, ela concede um meio de encontrar correlações nos dados, fornece ferramentas para visualizar as relações entre as variáveis de controle e as variáveis de resposta e oferece diversas vantagens sobre outras formas de análise o que confere maior assertividade nos processos decisórios. (NANOTIMIZE, 2012)
\end{abstract}

Normalmente, para fazer a estimação do VAR, as variáveis são diferenciadas tantas vezes quanto necessário (em geral duas vezes), de modo a verificar sua estacionariedade. Esta diferenciação pode, no entanto, mascarar a cointegração. Se há presença de cointegração, o mais adequado é a estimação de um modelo com vetor de correção de erros (VEC). Na verdade, se objetiva determinar as interrelações entre as variáveis e não a estimativa dos parâmetros propriamente.

Pode-se representar um VAR através da seguinte expressão, para dois processos estocásticos:

O que equivale a:

$$
\left\{\begin{array}{l}
y_{t}=a_{10}+a_{11} y_{t-1}+a_{12} z_{t-1}+\varepsilon_{1 t} \\
z_{t}=a_{20}+a_{21} y_{t-1}+a_{22} z_{t-1}+\varepsilon_{2 t}
\end{array}\right.
$$

$$
x_{t}=A_{0}+A_{1} x_{t-1}+\varepsilon_{t}
$$

Para um VAR com $n$ processos estocásticos tem-se:

$$
x_{t}=A_{0}+A_{1} x_{t-1}+A_{2} x_{t-2}+\ldots+A_{n} x_{n-1}+\varepsilon_{t}
$$

Pode-se escrever a equação (1) da seguinte forma:

$$
y_{t}=\beta x_{t}+\varepsilon_{t}
$$

Se $x$ e $y$ são cointegrados, a combinação linear deles gera um vetor $\beta$ de parâmetros que produzirá resíduos estacionários. Caso não haja cointegração, usa-se um modelo de vetores auto-regressivos e diz-se que $x$ explica $y$ na relação contemporânea. Caso haja simultaneidade de explicação tem-se que as variáveis são endógenas.

Considerando o problema relatado, o modelo econométrico apresenta-se na forma:

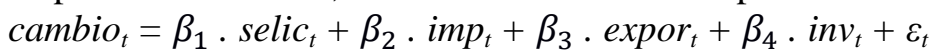

através do qual procura-se verificar se as variações da taxa de câmbio (R $\$ / U \$$ ) podem ser explicadas pelas variáveis:

- selic: corresponde à taxa Selic, em percentual. Os dados utilizados dizem respeito à média anual;

- imp: diz respeito ao valor FOB (Free On Board) das importações brasileiras em milhões de dólares;

- expor: refere-se ao valor FOB das exportações brasileiras em milhões de dólares;

- inv: representa o valor dos investimentos estrangeiros no país em milhões de dólares. 
Contudo, a utilização de modelos VAR está condicionada a premissa básica de que as séries temporais analisadas devem ser estacionárias, caso contrário, a regressão será espúria. Dessa forma, o processo de estimação de um modelo VAR deve passar por uma sequência de etapas pré-definidas que indicarão o caminho a ser seguido e levarão a um resultado correto e significativo. Num primeiro momento deve ser verificada a estacionariedade das séries através do teste da Raiz Unitária. Confirmada essa condição, deve-se determinar a melhor ordem de defasagens a ser utilizada na estimação do modelo e fazer os testes de cointegração, que indicarão a utilização de um VAR ou um VEC. Definido isso, o passo final é estimar o modelo escolhido e analisar a qualidade e o poder de previsão do ajuste.

\section{Análise econométrica}

Para a análise e ajuste do modelo econométrico, foram utilizadas cinco séries de tempo (taxa de câmbio, taxa Selic, importações, exportações e investimentos estrangeiros), em termos anuais, referentes ao período de 1974 a 2012 obtidas através do site http://www.ipeadata.gov.br/ e simuladas através de software específico para a análise e previsão econométrica, no caso o EViews ${ }^{\circledR}$.

A Figura 1 ilustra o comportamento dessas séries através de gráficos e permite verificar, de forma intuitiva, a estacionariedade delas.

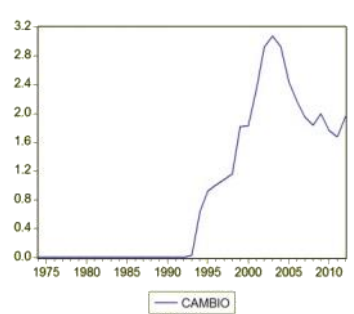

(a)

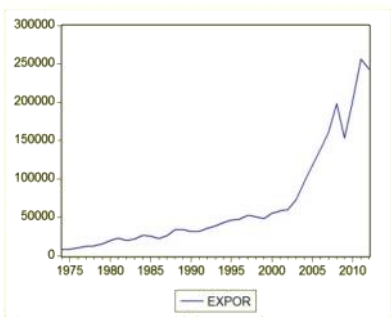

(d)

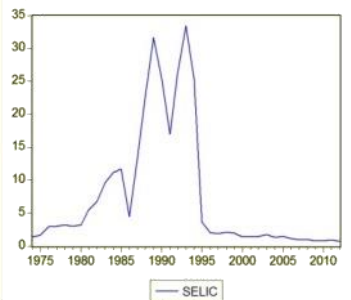

(b)

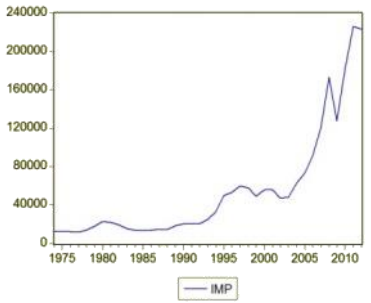

(c)

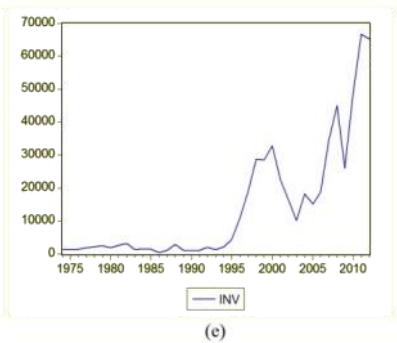

Figura 1: (a) Comportamento da série de tempo cambio. (b) Comportamento da série de tempo selic. (c) Comportamento da série de tempo imp. (d) Comportamento da série de tempo expor.

(e) Comportamento da série de tempo inv.

Fonte: Os autores.

Entretanto, para garantir a confiabilidade do modelo, é necessária a realização de testes específicos para a estacionariedade, que tem como base o teste da Raiz Unitária. A raiz unitária pode ser analisada através de diferentes testes, entre eles Augmented Dickey-Fuller (ADF) e Phillips-Perron (PP), nos quais o Teste de Hipóteses é:

$$
\left\{\begin{array}{c}
\mathrm{H}_{\mathrm{O}}: \exists \text { raiz unitária e a série não é estacionária } \\
\mathrm{H}_{1}: \nexists \text { raiz unitária e a série é estacionária }
\end{array}\right.
$$

A fim de verificar a característica de estacionariedade, as séries foram submetidas ao teste Phillips-Perron. A Tabela 1 mostra os resultados obtidos com a realização do teste, em primeira diferença, pois verificou-se que em nível, para os três tipos indica que a hipótese nula não deve ser rejeitada, uma vez que $|\mathrm{t}|<$ valor crítico para os níveis de confiança considerados e, portanto, as séries são não estacionárias. 


\begin{tabular}{|c|c|c|c|c|c|c|c|}
\hline \multirow{2}{*}{ Tipos } & \multirow{2}{*}{$\begin{array}{c}\text { Nível de } \\
\text { significância }\end{array}$} & \multirow{2}{*}{$\begin{array}{l}\text { Valores } \\
\text { críticos }\end{array}$} & \multicolumn{5}{|c|}{ t-Statistics } \\
\hline & & & cambio & selic & $i m p$ & expor & inv \\
\hline \multirow{3}{*}{$\begin{array}{c}\text { INTERC } \\
\text { EPT }\end{array}$} & $1 \%$ & -3.621023 & \multirow{3}{*}{-3.736588} & \multirow{3}{*}{-4.881996} & \multirow{3}{*}{-6.554588} & \multirow{3}{*}{-6.367183} & \multirow{3}{*}{-5.996341} \\
\hline & $5 \%$ & -2.943427 & & & & & \\
\hline & $10 \%$ & -2.610263 & & & & & \\
\hline \multirow{3}{*}{$\begin{array}{c}\text { TREND } \\
\text { AND } \\
\text { INTERC } \\
\text { EPT } \\
\end{array}$} & $1 \%$ & -4.226815 & \multirow{3}{*}{-3.680357} & \multirow{3}{*}{-5.296078} & \multirow{3}{*}{-7.642833} & \multirow{3}{*}{-7.692351} & \multirow{3}{*}{-6.324234} \\
\hline & $5 \%$ & -3.536601 & & & & & \\
\hline & $10 \%$ & -3.200320 & & & & & \\
\hline \multirow{3}{*}{ NONE } & $1 \%$ & -2.628961 & \multirow{3}{*}{-3.639177} & \multirow{3}{*}{-4.999059} & \multirow{3}{*}{-6.068288} & \multirow{3}{*}{-5.718568} & \multirow{3}{*}{-5.744687} \\
\hline & $5 \%$ & -1.950117 & & & & & \\
\hline & $10 \%$ & -1.611339 & & & & & \\
\hline
\end{tabular}

Tabela 1 - Resultados do teste Phillips-Perron, em primeira diferença, para os três tipos das cinco séries temporais consideradas no modelo.

Fonte: Os autores.

Pela Tabela 1 nota-se que todas as séries tornam-se estacionárias em primeira diferença, visto que $|\mathrm{t}|>$ valor crítico e, dessa forma, a hipótese nula é rejeitada. A série câmbio alcançou a estacionariedade com um nível de confiança de $95 \%$, enquanto as séries selic, imp, expor e inv a alcançaram com $99 \%$ de confiabilidade.

Após garantir essa condição, e como a amostra em questão conta com apenas 39 observações, o número ótimo de defasagens foi escolhido de acordo com o critério de Akaike (AIC - Akaike Information Criterion), utilizado para amostras pequenas. Verifica-se que, de acordo com o teste, as defasagens devem ser de ordem três, o que significa que os efeitos que a variável exógena tem sobre as endógenas duram três períodos.

O teste de cointegração (ou Teste de Johansen), realizado a seguir, apontou que o modelo que melhor se ajusta aos dados é um modelo VEC, pois de acordo com o mesmo critério de Akaike, as séries apresentam três vetores de cointegração num modelo quadrático, com intercepto e tendência. Dessa forma, a estimação do modelo econométrico ocorreu a partir de um vetor de correção de erros.

A Tabela 2 descreve os parâmetros estimados do modelo para longo prazo e a Tabela 3 exibe a estimação dos parâmetros para curto prazo. Os valores que aparecem entre parênteses referem-se ao erro padrão e entre colchetes está o valor da estatística t.

Os resultados para $\mathrm{R}^{2}$ e $\mathrm{R}^{2}$ ajustado podem ser vistos na Tabela 4.

\begin{tabular}{c|c|c|c}
\hline \hline Cointegrating Eq: & CointEq1 & CointEq2 & CointEq3 \\
\hline \hline cambio $(-1)$ & 1.000000 & 0.000000 & 0.000000 \\
\hline selic $(-1)$ & 0.000000 & 1.000000 & 0.000000 \\
\hline imp $(-1)$ & 0.000000 & 0.000000 & 1.000000 \\
\hline & $1.97 \mathrm{E}-05$ & 0.000192 & -0.734081 \\
expor $(-1)$ & $(5.5 \mathrm{E}-06)$ & $(0.00011)$ & $(0.04674)$ \\
& {$[3.58834]$} & {$[1.74836]$} & {$[-15.7070]$} \\
\hline & $-4.91 \mathrm{E}-05$ & 0.000161 & -0.906623 \\
inv $(-1)$ & $(1.3 \mathrm{E}-05)$ & $(0.00026)$ & $(0.11215)$ \\
& {$[-3.72623]$} & {$[0.61131]$} & {$[-8.08410]$} \\
\hline @trend (74) & -0.125469 & -0.854561 & 673.0728 \\
\hline$c$ & 1.055374 & -4.894952 & -7069.004 \\
\hline \hline
\end{tabular}

Tabela 2 - Parâmetros estimados do modelo VEC para longo prazo.

Fonte: Os autores.

Percebe-se que em primeira diferença, as variáveis são cointegradas, e, sendo assim, em termos econômicos, a Tabela 2 mostra que mudanças no valor do dólar devem-se especialmente as alterações nas exportações e nos investimentos estrangeiros em longo prazo, sendo que as 
demais variáveis apontam não ser possível observar um equilíbrio integrado num dado ponto no tempo. Pode-se ainda perceber que a taxa Selic e importações cointegram para a equação 2 e 3 , respectivamente.

\begin{tabular}{|c|c|c|c|c|c|}
\hline $\begin{array}{l}\text { Correção de } \\
\text { Erros }\end{array}$ & $d($ cambio $)$ & $d($ selic $)$ & $d(\mathrm{imp})$ & $d($ expor $)$ & $d(i n v)$ \\
\hline$d(\operatorname{cambio}(-2))$ & $\begin{array}{c}-0.081214 \\
(0.24044) \\
{[-0.33777]}\end{array}$ & $\begin{array}{c}-4.553659 \\
(5.99290) \\
{[-0.75984]}\end{array}$ & $\begin{array}{c}-28555.32 \\
(20876.7) \\
{[-1.36781]}\end{array}$ & $\begin{array}{c}-32574.19 \\
(15271.4) \\
{[-\mathbf{2 . 1 3 3 0 2}]}\end{array}$ & $\begin{array}{c}-22639.14 \\
(8614.08) \\
{[-\mathbf{2 . 6 2 8 1 5}}\end{array}$ \\
\hline$d(\operatorname{cambio}(-3))$ & $\begin{array}{c}-0.501729 \\
(0.27509) \\
{[-\mathbf{1 . 8 2 3 8 6}} \\
\end{array}$ & $\begin{array}{c}-1.695365 \\
(6.85658) \\
{[-0.24726]} \\
\end{array}$ & $\begin{array}{c}-34235.67 \\
(23885.4) \\
{[-1.43333]}\end{array}$ & $\begin{array}{c}-32761.84 \\
(17472.3) \\
{[-1.87507]}\end{array}$ & $\begin{array}{c}-11810.93 \\
(9855.52) \\
{[-1.19841]}\end{array}$ \\
\hline$d(\operatorname{selic}(-1))$ & $\begin{array}{l}0.024724 \\
(0.01065) \\
{[\mathbf{2 . 3 2 0 8 5}]}\end{array}$ & $\begin{array}{c}0.179365 \\
(0.26553) \\
{[0.67551]}\end{array}$ & $\begin{array}{c}-642.7101 \\
(924.978) \\
{[-0.69484]}\end{array}$ & $\begin{array}{c}50.44266 \\
(676.625) \\
{[0.07455]}\end{array}$ & $\begin{array}{c}-364.7381 \\
(381.661) \\
{[-0.95566]}\end{array}$ \\
\hline$d(i m p(-2))$ & $\begin{array}{c}-1.77 \mathrm{E}-06 \\
(1.1 \mathrm{E}-05) \\
{[-0.16105]}\end{array}$ & $\begin{array}{c}0.000661 \\
(0.00027) \\
{[2.41350]}\end{array}$ & $\begin{array}{c}-0.755513 \\
(0.95439) \\
{[-0.79161]}\end{array}$ & $\begin{array}{c}-0.383986 \\
(0.69814) \\
{[-0.55001]}\end{array}$ & $\begin{array}{c}-0.671756 \\
(0.39380) \\
{[\mathbf{- 1 . 7 0 5 8 3}}\end{array}$ \\
\hline$d(i m p(-3))$ & $\begin{array}{c}-2.33 \mathrm{E}-05 \\
(1.3 \mathrm{E}-05) \\
{[-1.75546]}\end{array}$ & $\begin{array}{l}0.001009 \\
(0.00033) \\
{[\mathbf{3 . 0 4 4 1 9}]}\end{array}$ & $\begin{array}{c}-0.950700 \\
(1.15423) \\
{[-0.82367]}\end{array}$ & $\begin{array}{c}-0.792108 \\
(0.84433) \\
{[-0.93816]}\end{array}$ & $\begin{array}{l}-0.050636 \\
(0.47626) \\
{[-0.10632]}\end{array}$ \\
\hline$d(\operatorname{expor}(-2))$ & $\begin{array}{c}7.38 \mathrm{E}-06 \\
(1.2 \mathrm{E}-05) \\
{[0.59113]}\end{array}$ & $\begin{array}{c}-0.000558 \\
(0.00031) \\
{[-1.79380]}\end{array}$ & $\begin{array}{c}-0.948155 \\
(1.08390) \\
{[-0.87476]}\end{array}$ & $\begin{array}{c}-1.526372 \\
(0.79288) \\
{[-\mathbf{1 . 9 2 5 1 0}]}\end{array}$ & $\begin{array}{l}0.000455 \\
(0.44724) \\
{[0.00102]}\end{array}$ \\
\hline$d(\operatorname{expor}(-3))$ & $\begin{array}{c}1.39 \mathrm{E}-05 \\
(1.3 \mathrm{E}-05) \\
{[1.08271]} \\
\end{array}$ & $\begin{array}{l}-0.001104 \\
(0.00032) \\
{[-\mathbf{3 . 4 5 5 8 5}]} \\
\end{array}$ & $\begin{array}{c}-0.155090 \\
(1.11260) \\
{[-0.13939]} \\
\end{array}$ & $\begin{array}{c}-0.549806 \\
(0.81387) \\
{[-0.67554]} \\
\end{array}$ & $\begin{array}{c}-0.304686 \\
(0.45908) \\
{[-0.66369]} \\
\end{array}$ \\
\hline$d(\operatorname{inv}(-1))$ & $\begin{array}{c}-1.89 \mathrm{E}-05 \\
(1.1 \mathrm{E}-05) \\
{[\mathbf{- 1 . 7 4 9 0 6}]} \\
\end{array}$ & $\begin{array}{c}-0.000719 \\
(0.00027) \\
{[-\mathbf{2 . 6 6 4 6 1}]} \\
\end{array}$ & $\begin{array}{c}2.272850 \\
(0.93938) \\
{[\mathbf{2 . 4 1 9 5 2}]} \\
\end{array}$ & $\begin{array}{c}1.714068 \\
(0.68716) \\
{[\mathbf{2 . 4 9 4 4 2}]} \\
\end{array}$ & $\begin{array}{c}0.907209 \\
(0.38760) \\
{[\mathbf{2 . 3 4 0 5 6}]} \\
\end{array}$ \\
\hline$c$ & $\begin{array}{l}0.056531 \\
(0.10797) \\
{[0.52357]} \\
\end{array}$ & $\begin{array}{l}3.259105 \\
(2.69119) \\
{[1.21103]} \\
\end{array}$ & $\begin{array}{c}-23869.70 \\
(9374.97) \\
{[-2.54611]} \\
\end{array}$ & $\begin{array}{c}-24754.89 \\
(6857.83) \\
{[-3.60973]}\end{array}$ & $\begin{array}{r}-8181.620 \\
(3868.27) \\
{[-2.11506]}\end{array}$ \\
\hline @ trend(74) & $\begin{array}{c}-0.001580 \\
(0.01111) \\
{[-0.14222]}\end{array}$ & $\begin{array}{c}-0.009401 \\
(0.27686) \\
{[-0.03396]}\end{array}$ & $\begin{array}{l}2710.589 \\
(964.461) \\
{[2.81047]}\end{array}$ & $\begin{array}{l}2940.590 \\
(705.507) \\
{[4.16805]}\end{array}$ & $\begin{array}{l}995.8042 \\
(397.953) \\
{[2.50232]}\end{array}$ \\
\hline
\end{tabular}

Tabela 3 - Parâmetros estimados do modelo VEC para curto prazo.

Fonte: Os autores.

Nota-se que em curto prazo, no modelo estimado, a taxa de câmbio contemporânea é afetada pela taxa de câmbio, taxa Selic, importações e investimentos estrangeiros em períodos defasados. A taxa de câmbio e as importações com ordem de defasagem três indicam que um aumento unitário no câmbio e nas importações defasados em três anos diminui o câmbio contemporâneo em - 0.501729 e $-2.33 \mathrm{E}-05$, respectivamente. Da mesma forma, segue que um aumento unitário na taxa Selic defasada em um ano aumenta o câmbio contemporâneo em 0.024724 , enquanto que um aumento unitário nos investimentos estrangeiros defasados em um ano diminui o câmbio contemporâneo em -1.89E-05. As exportações defasadas parecem não afetar a taxa de câmbio contemporânea.

Ainda, a taxa Selic contemporânea é afetada pelas importações, exportações e investimentos estrangeiros em períodos defasados. As importações e exportações com ordem de defasagem três indicam que um aumento unitário nas importações e nas exportações defasadas em três anos aumenta e diminui a taxa Selic em 0.001009 e -0.001104, respectivamente. Já um aumento unitário nos investimentos estrangeiros defasados em um ano diminui a taxa Selic em 0.000719. As importações em tempo contemporâneo parecem ser afetadas somente pelos 
investimentos estrangeiros defasado em um ano, de forma que um aumento unitário neles impacta num aumento de 2.272850 sobre as importações.

As exportações são influenciadas pela taxa de câmbio, exportações e investimentos estrangeiros defasados no tempo. Um aumento unitário no câmbio e nas exportações defasados em dois anos diminui as exportações contemporâneas em -32574.19 e -1.526372, respectivamente. Todavia, um aumento unitário nos investimentos defasados em um ano tem um impacto positivo nas exportações em 1.714068 .

Finalmente, os investimentos estrangeiros em tempo contemporâneo sofrem influência das variáveis câmbio, importações e investimentos defasadas no tempo. A taxa de câmbio e as importações defasadas em dois anos, ao sofrer um aumento unitário afetam os investimentos negativamente em -22639.14 e -0.671756, respectivamente. Porém, um aumento unitário dos investimentos estrangeiros defasados em um ano elevam os investimentos contemporâneos em 0.907209 .

\begin{tabular}{c|c|c|c|c|c}
\hline \hline & $d$ (cambio) & $d$ (selic) & $d$ (imp) & $d$ (expor) & $d$ (inv) \\
\hline \hline $\mathbf{R}^{\mathbf{2}}$ & 0.811537 & 0.790424 & 0.736492 & 0.847442 & 0.756829 \\
\hline $\mathbf{R}^{2}$ ajustado & 0.572817 & 0.524962 & 0.402716 & 0.654203 & 0.448813 \\
\hline \hline
\end{tabular}

Tabela 4 - Valores do $\mathrm{R}^{2}$ e $\mathrm{R}^{2}$ ajustado obtidos com a estimação do modelo VEC.

Fonte: Os autores.

Os valores de $\mathrm{R}^{2}$ sugerem que o ajuste é satisfatório para modelar o as variações da taxa de câmbio em função das variáveis taxa Selic, importações, exportações e investimentos estrangeiros no país.

\section{Considerações Finais}

A partir dos testes e análises supracitados, constata-se que todas as variáveis escolhidas afetam decisivamente o valor do dólar no Brasil. A curto prazo a taxa Selic e os investimentos estrangeiros no país afetam mais fortemente enquanto as importações e exportações influenciam de maneira mais forte a longo prazo. Em curto prazo, as variáveis importações e investimentos estrangeiros estão relacionadas à baixa do dólar, enquanto que a taxa Selic tem influência positiva no valor do câmbio. Apenas a variável exportações não apresenta indícios de que possa afetar de alguma maneira a taxa de câmbio.

Além disso, o modelo se mostrou adequado caso fosse necessária a estimação do dólar para curtos períodos haja vista que representa de maneira satisfatória o comportamento do dólar bem como das variáveis que o descrevem. Tal modelo pode ser aprofundado e melhorado especialmente quanto a estimação dos resíduos e da construção de um modelo que possa estimar com maior precisão a partir das variáveis que o caracterizam.

\section{Referências}

BLANCHARD, Olivier. Macroeconomia. Rio de Janeiro: Campus, 1999.

CAVALCANTI, Marco A.F.H. Identificação de Modelos VAR de Granger: uma nota de advertência. Economia Aplicada: 2010. v. 14; n. 2, p.251-260. Disponível em: <http://www.scielo.br/pdf/ecoa/v14n2/a08v14n2.pdf>. Acesso em: 03 set. 2013.

NANOTIMIZE. Análise Multivariada. 2012. Disponível em: <http://nanotimize.com.br/cases/case_03.pdf>. Acesso em: 05 set. 2013.

CARNEIRO, Francisco Galrão. A Metodologia dos Testes de Causalidade em Economia. Departamento de Economia (UnB). Disponível em: <http://www.angelfire.com/id/SergioDaSilva/causal.pdf >. Acesso em: 05 set. 2013. 